Journal of Current and Advance Medical Research

July 2021, Vol. 8, No. 2, pp. 114-118

http://www.banglajol.info/index.php/JCAMR ISSN

(Print) 2313-447X

ISSN (Online) 2413-323X

NLM Catalog ID 101673828

DOI: https://doi.org/ 10.3329/jcamr.v8i2.57436

ORIGINAL ARTICLE open 2 ACcess

\title{
Comparison of Ultrasonographic Evaluation of Gallbladder Volume in Type II Diabetic Patients with Non-diabetic Healthy Subjects
}

\author{
Nushrat Jahan Tahnia ${ }^{1}$, Mohammad Shakhawat Hossain ${ }^{2}$, Saneat Jahan Khan ${ }^{3}$, Md. Shahadat \\ Hossain $^{4}$
}

${ }^{1}$ Consultant, Radiology Department, Abeda Hospital, Dhaka, Bangladesh; ${ }^{2}$ Assistant Professor, Department of Plastic Surgery, Sher-E-Bangla Medical College, Barisal, Bangladesh; ${ }^{3}$ Assistant Professor, Department of Plastic Surgery, Bangabandhu Sheikh Mujib Medical College, Faridpur, Bangladesh; ${ }^{4}$ Lecturer, Department of Pathology, Dhaka Medical College, Dhaka, Bangladesh

[Received on: 11 April 2021; Accepted on: 2 My 2021; Published on: 1 July 2021]

Abstract

Background: Measurement of increased gallbladder volume is necessary for the detection of pathology of gallbladder. Objective: The purpose of the present study was to find out the difference between ultrasonographically measured gall bladder volume in fasting and post prandial states of type II diabetic patients and non-diabetic control subjects. Methodology: This cross-sectional study, carried out department of Radiology and Imaging at Bangladesh Institute of Research and Rehabilitation in Diabetes, Endocrine and Metabolic Disorders (BIRDEM) Hospital, Dhaka, Bangladesh from June 2013 to July 2014. The type II diabetic patients were selected as group A and the healthy individual with age and sex matched were selected as group B. An ultrasonographic evaluation of fasting gallbladder volume and 2 hours after meal was done in all the subjects using a $3.5 \mathrm{MHz}$ transducer. Information was recorded in preformed data collection sheet. Results: There was statistically significant $(p<0.001)$ difference of mean fasting gall bladder volume between diabetic and non-diabetic subjects. The mean postprandial gall bladder volume of type II diabetic patients was significantly higher than that of the non-diabetic controls. By using Karl-Pearson coefficients of correlation it was found that gallbladder enlargement in type II diabetics, was significantly correlated with body mass index $(\mathrm{p}=0.05)$ and systolic blood pressure $(\mathrm{p}=$ 0.05). Conclusions: Cholecystomegaly is found in type II diabetics in the present study to a significant degree which is also significantly correlated with body mass index and systolic blood pressure. [Journal of Current and Advance Medical Research, July 2021;8(2):114-118]

Keywords: Ultrasonography; Gallbladder Volume; Type II Diabetes

Correspondence: Dr. Nushrat Jahan Tahnia. Consultant, Radiology Department, Abeda Hospital, Dhaka, Bangladesh; Email: tahniaj10@gmail.com; Cell no.: +8801711429067

Cite this article as: Tahnia NJ, Hossain MS, Khan SJ, Hossain MS. Comparison of Ultrasonographic Evaluation of Gallbladder Volume in Type II Diabetic Patients with Non-diabetic Healthy Subjects. J Curr Adv Med Res 2021;8(2):114-118

Funding: This study has been performed without any funding from outside else.

Conflict of Interest: There was no conflict of interest to any of the authors.

Contributions to authors: Tahnia NJ, Hossain MS had incvolved in the protocol preparation, data collection, statistical analysis as well as the report writing. Khan SJ, Hossain MS involved in the manuscript preparation as well as manuscript correction. All authors were responsible for the research works.

Copyright: (02021. Tahnia et al. Published by Journal of Current and Advance Medical Research. This article is published under the Creative Commons CC BY-NC License (https://creativecommons.org/licenses/by-nc/4.0/). This license permits use, distribution and reproduction in any medium, provided the original work is properly cited, and is not used for commercial purposes. 


\section{Introduction}

Diabetes mellitus is a group of metabolic disease characterized by hyperglycemia resulting from defects in insulin secretion, insulin action or both ${ }^{1}$. The chronic hyperglycemia of diabetes is associated with long term damage, dysfunction and failure of various organs especially the eyes, kidneys, nerves, heart, gallbladder and blood vessels; however, an estimated 366 million people, corresponding to $8.3 \%$ of the world's adult population, live with diabetes $^{2}$. The number is expected to grow 552 million by $2030^{3}$. Prevalence of diabetes in Bangladesh reported from $4.0 \%$ to $13.0 \%$ among adults ${ }^{4}$. Bangladesh currently has over three million people with diabetes and this number will reach 11 million by the year $2030^{5}$. Various studies point towards an increased prevalence of gallbladder disease in diabetics ${ }^{3}$. This has been attributed to cholecystomegaly and impaired gall bladder contraction, mainly due to autonomic neuropathy seen in diabetics ${ }^{6-7}$.

Although exact path physiologic basis of gallbladder dysfunction in diabetes is yet not clear, motor abnormalities of gallbladder function is one of the proposed mechanisms. These motor abnormalities include large size and impaired contractility of gall bladder due to vagal visceral neuropathy. Gallbladder enlargement may occur in other disorders such as distal biliary obstruction, chronic pancreatitis, and primary sclerosing cholangitis ${ }^{8}$. Therefore, evaluation of increase gallbladder volume is necessary to find out pathology of gallbladder itself as well as others.

Beyond other radiological procedure ultrasonography has been chosen as the modality to assess gallbladder volume, as it is $95.0 \%$ accurate to evaluate gallbladder and billiary tree, it is safe, inexpensive, less time consuming, accurate, painless ${ }^{9}$. The best non-invasive test for detecting gallstones in the gallbladder, does not require special preparation, although it is technically easier in patients with at least six hours of fasting, It is highly specific and sensitive $(90.0 \%$ to $95.0 \%)$ which does not employ ionizing radiation. It may also indicate distal obstruction by the finding of dilated intrahepatic or extra hepatic bile duct ${ }^{10}$.

Since gallbladder abnormalities usually remain clinically silent among diabetics, patients may suddenly present with catastrophic complications like acute cholecystitis requiring emergency cholecystectomy. People with diabetes are usually considered high-risk for any surgery, including gallbladder surgery. However, in most cases, when gallstones are problematic, the best course of action is to remove the gallbladder ${ }^{11}$. In Bangladesh ultrasonogram of whole abdomen is routinely used investigation in diabetic patient. If gallbladder volume is measured at the same time as well as other organs, early evaluation of enlarge gallbladder can be possible. The purpose of the present study was to compare the gallbladder volume between the diabetic and non-diabetic individuals by ultrasonography.

\section{Methodology}

This was comparative cross-sectional study which was carried out in the Department of Radiology and Imaging at Bangladesh Institute of Research and Rehabilitation in Diabetes, Endocrine and Metabolic Disorders (BIRDEM) Hospital, Dhaka, Bangladesh from June 2013 to July 2014 for a period of one year. All the type II diabetic patients with the age group of more than or equal to 18 years in both sexes were enrolled in this study. Purposive sampling method was followed. An ultrasonographic evaluation of fasting gallbladder volume and 2 hours after meal was done in all the subjects using a $3.5 \mathrm{MHz}$ transducer. The blood glucose was measured to all patients. All the required information about the patients were recorded in preformed data collection sheet. Then the data were compiled and analyzed. Ethical clearance was obtained from Local Institutional Review Board (IRB).

\section{Results}

For this purpose, 148 diabetic patients were taken as study group and 148 healthy subjects were included as control. The mean age of the nondiabetic healthy control subjects was $46.71 \pm 12.58$ years and that of the cases was $45.09 \pm 12.01$ years. In both groups the age almost followed a normal distribution. No significant difference was observed between these two groups $(\mathrm{p}=0.259)$.

A total of 148 healthy normal subjects were included in the study. They were divided into five age groups. The mean age was 46.71 years with standard deviation $(\mathrm{SD}) \pm 12.58$ years and their age ranged from 23 to 77 years in control group. Maximum numbers (53/148) were found in the age group of 31-40 years. A total of 148 type II diabetic patients were included in the study. They were divided into five age groups. The mean age was 45.09 years with standard deviation $(\mathrm{SD}) \pm 12.01$ years. Maximum numbers (53/148) were found in the age group of 31-40 years (Table 1). 
Table 1: Age Distribution among Study Population $(n=148)$

\begin{tabular}{|l|c|c|}
\hline Age Group & Group A & Group B \\
\hline$\leq 30$ Years & $9(6.1 \%)$ & $9(6.1 \%)$ \\
\hline 31 to 40 Years & $53(35.8 \%)$ & $53(35.8 \%)$ \\
\hline 41 to 50 Years & $40(27.0 \%)$ & $40(27.0 \%)$ \\
\hline 51 to 60 Years & $23(15.5 \%)$ & $23(15.5 \%)$ \\
\hline More Than 60 Years & $23(15.5 \%)$ & $23(15.5 \%)$ \\
\hline Total & $\mathbf{1 4 8}(\mathbf{1 0 0 . 0} \%)$ & $\mathbf{1 4 8}(\mathbf{1 0 0 . 0 \%})$ \\
\hline Mean \pm SD & $45.09 \pm 12.01$ & $46.71 \pm 12.58$ \\
\hline
\end{tabular}

Group $\mathrm{A}=$ type II DM patients; group $\mathrm{B}=$ healthy control; $\mathrm{p}$ $>0.05$

The mean fasting gall bladder volume of nondiabetic controls was $14.55 \pm 3.05 \mathrm{ml}$ (mean SD), ranged 10.04-25.33 ml and the mean fasting gall bladder volume of type II diabetic patients was $27.57 \pm 1.08 \mathrm{ml}$ (mean $\pm \mathrm{SD}$ ), ranged 22.10-35.00 $\mathrm{ml}$. There was statistically significant $(\mathrm{p}<0.001)$ difference of mean fasting gall bladder volume between diabetic and non-diabetic subjects in student " $t$ " test.

The mean postprandial gall bladder volume of nondiabetic controls was $12.33 \pm 4.73 \mathrm{ml}$ (mean SD), ranged 4.04-20.62 $\mathrm{ml}$ and the mean fasting gall bladder volume of type II diabetic patients was $16.38 \pm 3.72 \mathrm{ml}$ (mean $\pm \mathrm{SD}$ ), ranged 8.04-25.76 $\mathrm{ml}$. There was statistically significant $(\mathrm{p}<0.001)$ difference of mean postprandial gall bladder volume between diabetic and non-diabetic subjects in student " $t$ " test (Table 2)

Table 2: Comparison between fasting gall bladder volume of diabetic and non-diabetic patients $($ Mean \pm SD)

\begin{tabular}{|l|c|c|c|}
\hline \multirow{2}{*}{ Group } & \multicolumn{2}{|c|}{ Gall Bladder Volume (mL) } & \multirow{2}{*}{ P value } \\
\cline { 2 - 3 } & Fasting & Postprandial & \\
\hline Type II & $27.57 \pm 1.08$ & $16.38 \pm 3.72$ & 0.001 \\
diabetic & $(22.10-$ & $(8.04-25.76)$ & \\
patients & $35.00)$ & & \\
(n=148) & & & \\
\hline $\begin{array}{l}\text { Non- } \\
\text { diabetic }\end{array}$ & $14.55 \pm 3.05$ & $12.33 \pm 4.73$ & 0.001 \\
control & $25.33)$ & $(4.04-20.62)$ & \\
$(\mathrm{n}=148)$ & & & \\
\hline
\end{tabular}

When Karl-Pearson coefficients of correlation were calculated for gallbladder volume with various parameters, it was found that gallbladder enlargement in type II diabetics, was significantly correlated with body mass index $(\mathrm{p}=0.05)$ and systolic blood pressure $(\mathrm{p}=0.05)$ (Table 3$)$.
Table 3: Pearson co-efficient of fasting and postprandial gallbladder volume with study parameters $(\mathbf{n}=\mathbf{2 9 6})$

\begin{tabular}{|l|c|c|c|c|}
\hline Variables & \multicolumn{2}{|c|}{$\begin{array}{c}\text { Fasting } \\
\text { Gallbladder } \\
\text { volume }\end{array}$} & \multicolumn{2}{c|}{$\begin{array}{c}\text { Postprandial } \\
\text { Gallbladder } \\
\text { volume }\end{array}$} \\
\cline { 2 - 5 } & $\mathbf{r}$ & P value & r & P value \\
\hline Age & 0.031 & 0.601 & -.042 & 0.477 \\
\hline BMI & 0.112 & 0.05 & 0.094 & 0.108 \\
\hline sBP & -.114 & 0.05 & -.046 & 0.427 \\
\hline dBP & -.074 & 0.267 & -.051 & 0.378 \\
\hline
\end{tabular}

\section{Discussion}

This cross-sectional study was done to find out the difference between ultrasonographically measured gall bladder volume in fasting and post prandial states of type II diabetic patients and non-diabetic control subjects in the department of Radiology and Imaging, Bangladesh Institute of Research and Rehabilitation in Diabetes, Endocrine and Metabolic Disorders (BIRDEM).

This study has been included 148 type II diabetic patients and 148 healthy subjects in the present study. Ultrasonographic evaluation of fasting gallbladder volume and 2 hours after meal was done in all the subjects using a $3.5 \mathrm{MHz}$ transducer. The mean age of the non-diabetic healthy control subjects was $46.71( \pm 12.58)$ years and that of the case patients was $45.09( \pm 12.01)$ years. Agarwal reported 50.9 years and 41.1 years for case and control groups respectively in their study (2004). In both groups about $60 \%$ were male. There was statistically significant $(\mathrm{p}<0.05)$ difference of mean SBP between diabetic and non-diabetic subjects in student " $t$ " test but no such difference was observe regarding diastolic blood pressure.

Widely believed reasons for the increased prevalence of gall stone disease in diabetics include decreased gall bladder motility, decreased postprandial cholecystokinin (CCK) release, decreased sensitivity of gall bladder smooth muscle to CCK, decreased number of CCK receptors in the gallbladder wall, supersaturation of bile, and the presence of gall stones themselves ${ }^{12}$. Neural control of gallbladder emptying is mediated by both parasympathetic and sympathetic innervation; the parasympathetic nerve increases gallbladder contractility and the sympathetic nerve causes relaxation. Food related release of CCK causes gallbladder contraction. The motility defects of gallstone patients are manifested by increased fasting volume, decreased ejection fraction, 
decreased rate of ejection, and increased residual volume of the gall bladder ${ }^{13}$.

In our study the mean fasting gall bladder volume of non-diabetic controls was $14.55 \pm 3.05 \mathrm{~mL}$ (mean SD), ranged $10.04-25.33 \mathrm{~mL}$ and the mean fasting gall bladder volume of type II diabetic patients was $27.57 \pm 1.08 \mathrm{ml}$ (mean $\pm \mathrm{SD}$ ), ranged 22.10-35.00 $\mathrm{ml}$. On the other hand, the mean postprandial gall bladder volume of non-diabetic controls was $12.33 \pm 4.73 \mathrm{~mL}$ (mean SD), ranged 4.04-20.62 $\mathrm{ml}$ and the mean fasting gall bladder volume of type II diabetic patients was $16.38 \pm 3.72$ $\mathrm{mL}$ (mean $\pm \mathrm{SD}$ ), ranged 8.04-25.76 mL. These differences were statistically significant. A number of other studies have shown increased fasting and post prandial gallbladder volumes in type II diabetics as compared to healthy controls ${ }^{6,13}$. These studies also measured gallbladder emptying as a measure of gallbladder motility and found that the gallbladder emptying was also reduced in diabetics. Due to logistical constraints it has not been studied gallbladder emptying, but if done, would have found similar findings.

Like Agarwal et $\mathrm{al}^{6}$ study gallbladder volume showed a positive correlation with body mass index in this study. Although none of our patients were obese, the finding is in accordance with the general trend of increasing gallbladder hypomotility with increasing body weight. The present study contradicts the findings of Agarwal et $\mathrm{al}^{6}$ by failing to find a positive correlation of age with gallbladder volume. Small sample size could be the cause of such discrepancy. Our study reminds the fact that diabetic cholecystopathy, which may predispose these patients to gallstone formation, is not uncommon, especially in type II diabetics.

All diabetics should be evaluated for the presence of increased fasting gallbladder volumes, impaired postprandial gallbladder emptying, and gallbladder sludging; all markers of risk of progression to overt gall stone disease. This leads to increased risk of the complications of gallstone disease or its treatment. A definite association of diabetes with cholecystomegaly has been demonstrated in previous studies ${ }^{14-15}$ and it implies a thorough evaluation for nerve impairment in all diabetic patients. Ultrasonography is a relatively cheap and painless imaging tool. It can be routinely used in type II diabetic patients for assessment of gallbladder volume and gallbladder emptying.

Like all other studies this study also had several limitations. Due to time constrain a relatively small sample size was taken for study. Assessment of interobserver variability was not possible due to the single observer study design. Due to logistical constraints it did not studied gallbladder emptying as a measure of gallbladder motility. Duration of diabetes and serum cholesterol level were also not included in the Karl-Pearson co-efficient analysis. This study should be viewed as preliminary one and a larger scale prospective study would be needed to confirm our conclusion.

\section{Conclusion}

In conclusion cholecystomegaly is found in type II diabetics in the present study to a significant degree which is also significantly correlated with body mass index and systolic blood pressure. The present study restates the fact that diabetic cholecystopathy is not uncommon in type II diabetics, which may predispose these patients to gallstone formation. Therefore, diabetic cholecystopathy is not uncommon in type II diabetics, which may predispose these patients to gallstone formation. Early detection of cholecsytomegaly may help prevent morbidity in type II diabetic patients. All diabetics should be evaluated for the presence of increased fasting gallbladder volumes, impaired postprandial gallbladder emptying and gallbladder sludging; all markers of risk of progression to overt gall stone disease.

\section{References}

1. Gospin R, Leu JP, Zonszein J. Diagnostic criteria and classification of diabetes. InPrinciples of Diabetes Mellitus: Third Edition 2017 Jul 7 (pp. 123-138). Springer International Publishing.

2. Saxena R, Sharma S, Dubey DC. Gallbladder disorder in type 2 diabetes mellitus cases. Journal of Human Ecology. 2005;18(3):169-71

3. Mbanya JC. Diabetes facts', International Diabetes Federation. IDF Diabetes Atlas, 6th edn. Brussels, Belgium, 2013; viewed 27 July 2014, Website: http://www.idf.org/diabetesatlas

4. Type 2 Diabetes and prediabetic conditions among adults aged 27-50 years in Matlab 2009, ICDDR,B, Health and Science Bulletin, vol. 7, no.2

5. Federation ID. IDF diabetes atlas. Brussels: International Diabetes Federation. 2013;128:40-50

6. Agarwal AK, Miglani S, Singla S, Garg U, Dudeja RK, Goel A. Ultrasonographic evaluation of gallbladder volume in diabetics. JAPI. 2004 Dec;52:963-67

7. Altaie AH. Association between Gallstones and Diabetics Type 2 Iraqi Patients. Iraqi J Pharm Sci. 2011;20(2):38-43.

8. Van de Meeberg PC, Portincasa P, Wolfhagen FH, Van Erpecum KJ, VanBerge-Henegouwen GP. Increased gall bladder volume in primary sclerosing cholangitis. Gut. 1996 Oct 1;39(4):594-9.

9. Adedin N, Shahriar AA, Mohiuddin AS, Sultana J, Ghafoor N. Comparison of ultrasonography and computed tomography to evaluate the causes of biliary obstruction. Eoroasian $\mathbf{J}$ Hepato-Gastroenterol. 2012;2:98-103 
10. Jarnagin WR. Blumgart's Surgery of the Liver, Biliary Tract and Pancreas. $5^{\text {th }}$ edn, 2012; Elsevier Inc., 225 Wyman Street, Waltham, MA, pp.1980-1985

11. Clavien PA, Baillie J, editors. Diseases of the gallbladder and bile ducts: diagnosis and treatment. John Wiley \& Sons; 2008 Apr 15

12. Colledge NR, Walker BR. Davidson's Principles and Practice of Medicine', 21 ${ }^{\text {st }}$ edn.,2012:922

13. Gaur P, Swanson SJ. Should we continue to drain the pylorus in patients undergoing an esophagectomy?. Diseases of the Esophagus. 2014 Aug 1;27(6):568-73.

14. Kayacetin E, Kisakol G, Kaya A, Akpinar Z. Real-time sonography for screening of gallbladder motility in diabetic patients: relation to autonomic and peripheral neuropathy. Neuroendocrinology Letters. 2003 Feb 1;24(1/2):73-6

15. Singh S, Chander R, Singh A, Mann S. Ultrasonographic evaluation of gall bladder diseases in diabetes mellitus type 2 . Indian Journal of Radiology and Imaging. 2006;16(4):110-118 